\title{
Representaciones de la etnia rarámuri en el muralismo de la ciudad de Chihuahua
}

\author{
Representations of the Rarámuri ethnic group at muralism in the \\ city of Chihuahua
}

Adán Erubiel Liddiard Cárdenas ${ }^{1}$ y Guillermo Hernández Orozco ${ }^{2}$

Fecha de recepción: 31 de agosto de 2020

Fecha de Aceptación: 12 de noviembre de 2020

1- Nacionalidad: Mexicana. Grado: Licenciado en Diseño Gráfico con Maestría en Docencia. Candidato a Doctor en Educación, Artes y Humanidades. Adscripción: Universidad Autónoma de Chihuahua. (DORCID: http://orcid.org/0000-00026572-024X. Correo electrónico: p166450@uach.mx

2- Nacionalidad: Mexicana. Grado: Doctor en Ciencias de la Educación. Adscripción: Universidad Autónoma de Chihuahua. DORCID: https://orcid.org/0000-0001-7287-8240. Correo electrónico: ghernand@uach.mx 


\section{Resumen}

El muralismo de la ciudad de Chihuahua, capital del estado homónimo al norte de México, exhibe una presencia importante de imágenes de la comunidad rarámuri, etnia originaria de esa región. El objetivo de este artículo es exponer la catalogación de las distintas formas de representación visual encontradas hacia esta insigne comunidad indígena, así como la reflexión detrás de cada una. Esto derivado del análisis anterior en una investigación doctoral hacia este objeto de estudio, con una metodología historio e iconográfica, y rescate fotográfico de las obras en el trabajo de campo. El resultado son siete distintas representaciones reconocibles de imágenes humanas rarámuri, dentro de contextos pasados o presentes, donde se concluye que para lograr el acercamiento a una visualización de un grupo indígena, se requieren de todas las ópticas posibles, inclusive artísticas.

Palabras clave: mural, población indígena, identidad cultural, regionalismo, historia social.

\section{Abstract}

Muralism in Chihuahua city, capital of the homonymous state in north of Mexico, exhibits a constant presence of Rarámuri community images, a regional native ethnic group. This article aims to expose the cataloging of the different visual representations found at this indigenous community, iconic in the region, and the reflection behind each of them. This is resulted from the previous analysis in a doctoral research for this object of study, working historiographic and iconographic methodology, and photographic rescue of the murals in fieldwork. The result is seven different and recognizable forms of representation at Rarámuri human images, past and present, concluding that, to achieve a close visualization of indigenous groups, it is necessary to take a look at all possible insights, even artistic.

Keywords: murals, indigenous peoples, cultural identity, regionalism, social history. 


\section{Introducción}

$\mathrm{E}$ 1 estado de Chihuahua, el más grande en extensión de México, tiene varios referentes culturales, económicos y geográficos que lo representan tanto dentro como fuera de su demarcación. Uno de estos referentes es la comunidad rarámuri, o tarahumara, la cual tiene mayor presencia en la Sierra Madre Occidental, o precisamente Sierra Tarahumara, como coloquialmente se le conoce, al suroeste del estado.

Descendientes de los primeros pobladores que llegaron desde Asia a América en grupos nómadas pequeños a través del Estrecho de Bering, hace aproximadamente 40 o 60 mil años, los rarámuri habitaban los valles centrales de la región, subsistiendo gracias a la cacería de animales pequeños, al cultivo de maíz, calabaza, chile y frijol, además de la recolección de frutos silvestres. A la llegada de los españoles fueron uno de los distintos pueblos prehispánicos encontrados en la zona, junto a los conchos, tepehuanes y tobosos (Sen Venero, 1999).

La comunidad rarámuri se ha visto reducida drásticamente a través del tiempo, debido principalmente a la represión armada en siglos pasados -que también los obligaría a reubicarse en partes altas de la serranía- y a la hambruna y enfermedades en tiempos más actuales, consecuencia de un rezago social estructural (Comisión Estatal para los Pueblos Indígenas, Julio de 2017), ubicándolos como un grupo vulnerable de Chihuahua.

Históricamente los levantamientos más relevantes de esta etnia acaecen en el siglo XVII, específicamente en 1648 y 1650, todos terminando con la muerte de misioneros jesuitas y franciscanos, y la automática respuesta del ejército español. Es en 1652 cuando la escalada de violencia aumenta, y los rarámuri, bajo el liderazgo del caudillo Gabriel Teporame, o Teporaca, realmente significan un peligro para la Nueva Vizcaya, lo que en ese momento eran los estados de Chihuahua, Coahuila y Nuevo México. El conflicto finaliza con la captura y ejecución del rebelde en 1653 (Sen Venero, 1999).

El aislamiento ha caracterizado a este pueblo indígena, entendido por la inaccesibilidad que brinda la topografía de la Sierra Tarahumara, y reflejado incluso en la organización social que desarrollan sus miembros, dispersa, con unidades familiares alejadas unas de otras. Gotés et al. (2010) lo mencionan como "pueblos cuyos habitantes no viven congregados en torno a un centro donde se ubique la iglesia, el mercado o las instancias de gobierno" (p. 75), incluso acotando que "solo se reúnen para celebrar sus fiestas" (p. 76).

De estas festividades, importantes para la relación interpersonal entre los rarámuri, son reconocidas las de Semana Santa, el Día de la Virgen de Guadalupe y el Día de la Candelaria. El consumo del batáli o tesgüino, bebida alcohólica a base de maíz fermentado, es un componente recurrente en estas. Por su parte, la interacción social se basa en la ayuda comunitaria con reciprocidad y cooperación, denominada kórima (Gotés et al., 2010).

Esta forma de vida relativamente aislada que lleva el rarámuri en el área serrana contrasta con lo que encuentra al migrar hacia las ciudades. La migración puede darse por motivos de educación, salud o conflictos personales, pero principalmente por la pobreza surgida de las sequías y la escasez de tierra cultivable (Morales, 2013).

En la actualidad, según datos de la Encuesta Intercensal 2015, el municipio de Chihuahua alcanzaba los 878,062 habitantes, de los cuales el $8.02 \%$ es una "población que se considera indígena" (Instituto 
Nacional de Estadística y Geografía, 2015, p. 43.), siendo entonces una comunidad con presencia importante en la capital del estado. Para 2019 eran siete los principales asentamientos rarámuri registrados en la urbe: El Oasis/Garí Rosácame, Pino Alto, Colonia Tarahumara, Siyóname Churuwy/Pájaro o Sierra Azul, Carlos Díaz Infante, Carlos Arroyo, y Sector Rarámuri de Rinconada los Nogales. El Oasis, el más antiguo, fue fundado por el reverendo Ezequiel Vargas y la Misión Evangelista Mexicana en 1957 (Morales, 2013; Solorio y Trujillo, 2019).

Los rarámuri dispersos en la ciudad, y los “de cierta forma encapsulados” (Morales, 2013, p. 30) en estos asentamientos, laboran principalmente en la albañilería, servicio doméstico o venta de artesanías; manteniendo una interacción cotidiana y enraizada, cultural, económica y social, con los demás habitantes no-indígenas de la ciudad, o chabochis -barbados- como les denominan en su lengua. Este intercambio continuo entre culturas, se da, en el mejor de los casos, dentro de su reconocimiento como población nativa y orgullo chihuahuense, lo que propicia que su inclusión como elemento visual y símbolo de la comunidad se dé en forma natural; tomando en cuenta también que esta etnia ha sido la imagen del propio estado durante décadas, con fines comerciales y turísticos sin beneficio para ellos (Morales, 2018), y a veces cayendo en el estereotipo.

Para este análisis de obra muralista, se observa en lo relativo a la comunidad rarámuri sus personas, usos y costumbres, como elementos más de ese entramado de regionalismos que dan forma a lo chihuahuense, o como acuña Espinoza (2004), chihuahuenidad. Los miembros de esta etnia -citadinos o serranos- aparecen de manera constante en esta rama del arte local, constituidos por su característico vestir y sus costumbres milenarias. Es en la reflexión hacia las similitudes y diferencias encontradas en estas variadas obras, que se visualiza el objetivo de este artículo: catalogar y reconocer el uso en cada representación rarámuri identificada en el muralismo chihuahuense.

\section{Metodología}

El presente artículo deviene de una investigación doctoral, dirigida hacia el muralismo en la ciudad de Chihuahua como objeto de estudio. Cualitativa de tipo teórica-empírica, dentro del paradigma interpretativo, y con un enfoque tanto histórico/historiográfico como iconográfico. Tiene al Método Iconográfico de Panofsky (1979) y sus niveles de análisis de la obra como eje teórico, basado en la comprensión de los elementos visuales primarios, la interpretación del mensaje y el análisis de su contexto. Se complementa con la teoría de Castiñeiras (2007) y Amador (2008) sobre simbología, composición y expresividad. Manejada en la horizontalidad, se abre a distintos ejes temáticos muralistas, desde los de instituciones gubernamentales, educativas y religiosas, hasta privados y urbanos, con múltiples ramificaciones de análisis de las cuales la representación rarámuri es solo una de ellas.

La recolección de datos se dio dentro del mismo trabajo de campo con: 1) Observación directa de todas las obras encontradas en un periodo de dos años y medio; 2) rescate fotográfico de todos los murales, ayudando a su conservación digital dado su carácter de efímeros, 3) historia oral extraída de quienes conocen o conviven con las pinturas; y 4) documentación bibliográfica y periodística enriquecedora del análisis iconográfico.

Dentro de este contexto, se seleccionaron para este artículo -de un universo de más de 2500 fotografías tomadas a aproximadamente 400 murales, conjuntos murales y grafitis presentados como murales- siete 
imágenes de obras en espacios públicos, las cuales ejemplifican la temática a reflexionar derivada de los resultados de dicha investigación. La variedad de temáticas permitió la comparación y clasificación entre diversas representaciones de la etnia rarámuri encontradas en los murales chihuahuenses.

\section{Las representaciones del rarámuri en el muralismo chihuahuense}

Caminar en la actualidad por las calles del Centro Histórico de la ciudad de Chihuahua, su eje geográfico cultural, supone una experiencia en varios niveles. Culinario por el encuentro con la comida local, artístico gracias a los músicos y actores callejeros, pero sin duda también visual al tener en un conjunto limitado de cuadras una cantidad considerable de murales. Esto se multiplica si se abre la visita a las zonas residenciales y periféricas de la ciudad, a sus locales comerciales, casas habitación, y edificios de gobierno, educativos y religiosos.

Es en los murales de esta mancha urbana en donde se observa una temática recurrente, gracias principalmente a esfuerzos gubernamentales en forma de programas, concursos y festivales, y esta es la exhibición de la identidad chihuahuense por medio de sus elementos visuales más reconocidos, siendo uno de estos la comunidad rarámuri. En múltiples obras actuales, la mayoría en el mencionado Centro Histórico, se percibe la personificación del tarahumara como un leitmotiv visual en las calles, resultando en rostros y vestimentas características de esta etnia diseminados a lo largo y ancho de la ciudad.

En la señalada investigación doctoral muralista en la ciudad de Chihuahua, se hizo visible que esta representación rarámuri, tanto en el Centro Histórico como en resto de la ciudad, presenta variantes perceptibles dependiendo del contexto o necesidades en las que el mural se realiza, o por el estilo pictórico característico del artista en turno y las influencias que muestra. Estos dos puntos giran en torno a la forma en la obra, pero es en la inseparable propiedad que lo acompaña, el contenido, en donde se encuentra el componente -característico del modelo de Jakobson- que configura mayoritariamente los elementos en la composición: el mensaje (Castiñeiras, 2007). A continuación se presentan las siete variantes encontradas para la representación de la etnia rarámuri.

\subsection{Histórica}

El mencionar al muralismo y la representación de etnias nativas lleva inequívocamente el pensamiento al indigenismo de la escuela muralista mexicana del siglo XX. Este indigenismo, llamado de segundo periodo, o institucionalizado, es una corriente cultural postrevolucionaria y espontánea al proyecto nacional del entonces Secretario de Instrucción Pública, José Vasconcelos. Desde su llegada significó una postura concebida para abordarse no solo desde lo antropológico, sino también desde otras disciplinas (Korsbaek y Sámano, 2007), como la fotografía, la cinematografía, y lo que fue su plataforma en la plástica: el muralismo.

Es el artista francés Jean Charlot quien fundamenta mucho de lo que esta vertiente significaría esos años, ya que como indica Collin (2003), él “creó el potente arquetipo del conquistador, que después sería 
retomado por tantos otros muralistas como Rivera, Siqueiros y Orozco" (p. 32). De esta forma, la tendencia a mostrar un indígena exaltado -similar al trabajo en las estampas nacionalistas de los calendarios de la época en México- se empieza a multiplicar, dado que "los muralistas idealizaron a la sociedad precolombina al tiempo que acentúan hasta la caricatura los rasgos negativos y sombríos de los conquistadores y de los misioneros" (p. 33).

El más mexicanista de los tres maestros muralistas, Diego Rivera, es quien acoge mejor este ideal en su obra. Este, un enamorado y conocedor del pasado prehispánico mexicano, y reconocido coleccionista de su arte (Garrido, 2009), da vida en sus trazos a personajes nativos de suma valentía y rasgos altivos, como los exhibidos en su mural de Palacio Nacional, Epopeya del pueblo mexicano, en la Ciudad de México.

Es dentro de este anecdotario como se desenvuelve la escuela muralista mexicana a lo largo de la primera mitad del siglo XX, reforzando sus fuertes lazos con el indigenismo. Aún en la actualidad, y a pesar del contrapeso reaccionario que significó pictóricamente para el nacionalismo vasconcelista la Generación de La Ruptura (Feria y Lince, 2010), este indigenismo continúa siendo inspiración en diversas partes del país, donde se resaltan las raíces nativas de México junto a visiones de protesta social. Ejemplo de esto presenta Ramírez (2020) con la investigación sobre la elaboración en 1998 del mural, Vida y sueños de la Cañada del Río Perla, en la ciudad de Taniperla, Chiapas. En este, los mismos habitantes de esa comunidad tzeltal reflejaron las raíces de su etnia en la fachada de la Casa Municipal, en un mural con lineamiento político y subversión social.

Pero volviendo a Chihuahua y la representación histórica de lo rarámuri, no existe un hilo de continuidad del muralismo postrevolucionario nacional en esta entidad más que en un par de casos perfectamente identificados, en donde la influencia de esta escuela muralista está documentada. Estos son el conjunto mural del Paraninfo de la Rectoría de la Universidad Autónoma de Chihuahua, y su similar del Palacio de Gobierno de Chihuahua, pintados por el duranguense Leandro Carreón, de 1937 a 1939, y el hidalguense Aarón Piña Mora, de 1958 a 1962, respectivamente (Rascón, 2011; Fernández y Sen Venero, 2013).

Los dos artistas, arraigados en Chihuahua, ofrecen en sus conjuntos murales recorridos históricos de forma estrictamente cronológica y lineal, mostrando un marcado indigenismo en los paneles que, según la narrativa de hechos, presentan tanto un significado de representación, o forma, como un significado intrínseco, o contenido (Panofsky, 1979). El contenido es aludido por el propio hecho histórico expuesto, mientras que la forma lo está en el tipo de representación que hacen de las etnias y su historia, siguiendo cánones de exaltación del personaje indígena vistos precisamente en la escuela muralista nacional, con cuerpos desnudos de marcada musculatura, actitud valiente y de rechazo al sometimiento español, y un cruel martirio en la defensa de sus tierras y poblaciones vejadas, como se observa en la imagen 1. 


\section{Imagen 1}

Panel del conjunto mural del Palacio de Gobierno de Chihuahua referente a Teporaca y los enfrentamientos entre nativos y españoles. Autor: Aarón Piña Mora

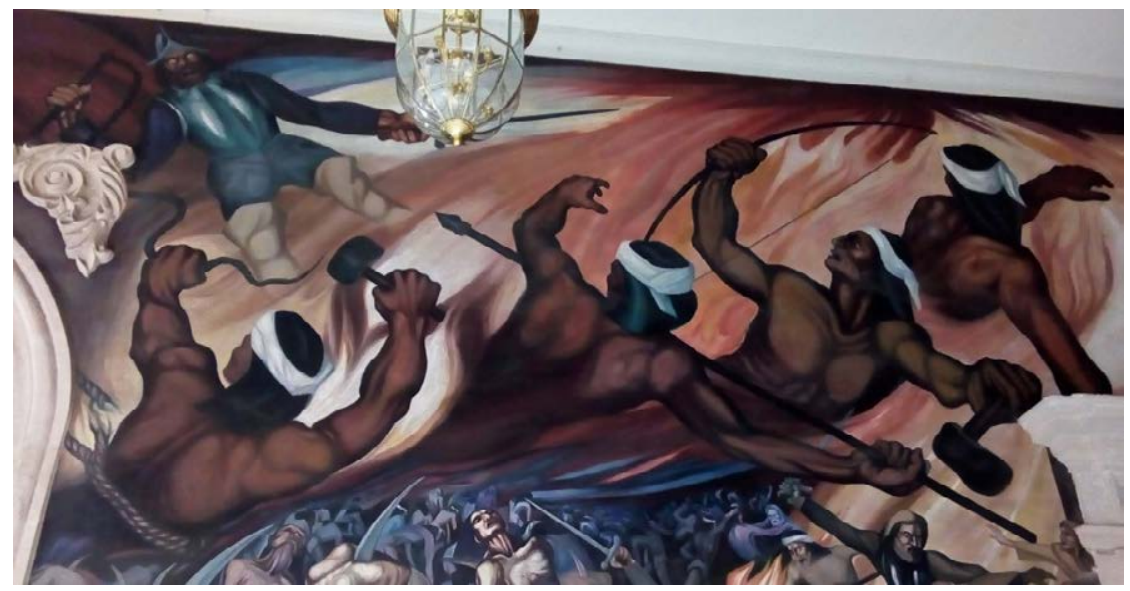

Fuente: (Liddiard, 2018).

En el caso del conjunto mural de Carreón, la representación se presenta hacia el pueblo azteca, al ser un trabajo narrativo de historia nacional. Sin embargo, en el conjunto mural realizado por Piña Mora en el Palacio de Gobierno sí se focalizan íntegramente las etnias prehispánicas chihuahuenses, principalmente la tarahumara, al tratarse de un compendio visual más cercano a la historia del estado que a la del país.

Existe además otro par de murales más contemporáneos que también ejemplifican en la localidad este tipo de representación. El primero, localizado en la fachada del Museo Tarike, y creado por Aguirre \& Co. en 2019, presenta un área introductoria a su también narrativa lineal de la historia de la ciudad, donde exhibe la grandeza de los pueblos originarios chihuahuenses, tarahumaras incluidos. El segundo se ubica en el Salón Consistorial del Palacio Municipal de Chihuahua, elaborado por el chihuahuense Alonso Enríquez en 2014, y titulado, La Fundación de Chihuahua. En las cuatro paredes en que se extiende relata este hecho histórico, haciendo múltiples alusiones a la etnia tarahumara como lejano actor de este relevante acontecimiento local.

Este último mural, sin embargo, tuvo veladas críticas por el visible anacronismo que presenta en el vestuario de los personajes tarahumaras, ya que es más cercano a lo usado en la actualidad que a en 1709, año del hecho histórico. Sobre este tema, Bajas (2006) expone, desde el punto de vista audiovisual, que debe existir una buena asociación entre el indígena y su pasado, ayudándose en una acertada documentación que "le otorga veracidad a la obra en construcción. La investigación recurre a archivos históricos con la clara intención de mostrar lo "verdadero", los hechos tal como fueron" (p. 14).

\subsection{Icónica}

Una representación de la etnia rarámuri muy utilizada en el estado de Chihuahua es como estampa tradicional de lo chihuahuense, no solo en el muralismo o el arte plástico en sí, sino incluso en la publicidad y mercadotecnia de marcas regionales, por medio de fotografías o ilustraciones digitales. Es decir, como ícono de la región, como ya se mencionó anteriormente. 
Aquí el retrato del miembro de esta comunidad, hombre o mujer, se relaciona intrínsecamente con el arraigo chihuahuense, atribuyéndose el autor y el espectador la pertenencia de una imagen ajena, al sentirla propia o representativa, en un tipo de apropiación cultural regionalista. Se puede explicar desde un enfoque de corresponsabilidad creativa, ya que "el realizador no actúa solo..., necesita de un espectador que comparta los mismos códigos socioculturales y que sea capaz de generar conjeturas propias de lo que se expone. Artista, obra y espectador son parte de un acto creativo" (Bajas, 2006, p. 12).

La identidad es un concepto que se ha estudiado desde la biología, la psicología, la filosofía y el lenguaje. Se puede explicar cómo las diferencias o similitudes, físicas o de comportamiento, que un individuo percibe de sí mismo en referencia con quien lo rodea. Esto se extiende de la persona a la pluralidad del grupo cuando adquiere la perspectiva de la sociología, como constructo sociohistórico, pasando del yo al nosotros en relación a los demás (İ̃niguez, 2001).

Esta identidad desde lo tarahumara, con sus rasgos característicos y coloridas vestimentas, pero rara vez su vulnerabilidad como grupo social, se suman a la ejecución de Hidalgo, a la travesía de Cabeza de Vaca, al asilo a Juárez, y al inicio de la Revolución, como elementos más de lo chihuahuense (Espinoza, 2004). La identidad rarámuri, que "se construye en la interacción a lo largo de la vida con todos los componentes que lo constituyen, habitantes, ocupaciones, leyes, usos y costumbres, integración étnica, migraciones, territorio, uso de suelo, condiciones políticas, sociales y culturales" (Escudero et al., 2019, p. 177), es incorporada visual y sistemáticamente en el imaginario común del chihuahuense, paradójicamente como cercana pero a la vez distante.

En el mural titulado, Cultura regional -parte del díptico, Diversidad cultural-, creado por el cuauhtemense Miguel Valverde en 2019 para el vestíbulo del Centro de Convenciones de Chihuahua, la imagen del tarahumara, ahora de manera estilizada, comparte el espacio con otros elementos icónicos de Chihuahua. Estos son naturales, como la Cascada de Basaseachi y la Cueva de los Cristales de Naica; otros son de hechura humana como el Ferrocarril Chepe; e incluso el autor exhibe productos agrícolas, como la manzana, el queso y la nuez; así como cabezas de ganado y la internacionalmente reconocida cerámica de Mata Ortiz, todo esto en la imagen 2. Este crisol de elementos conocidos ofrece un acercamiento a la cultura regional, como hace mención su título, forjada a través del tiempo y que mantiene el aspecto rarámuri en constante visualización.

\section{Imagen 2}

Mural, Cultura regional. Autor: Miguel Valverde

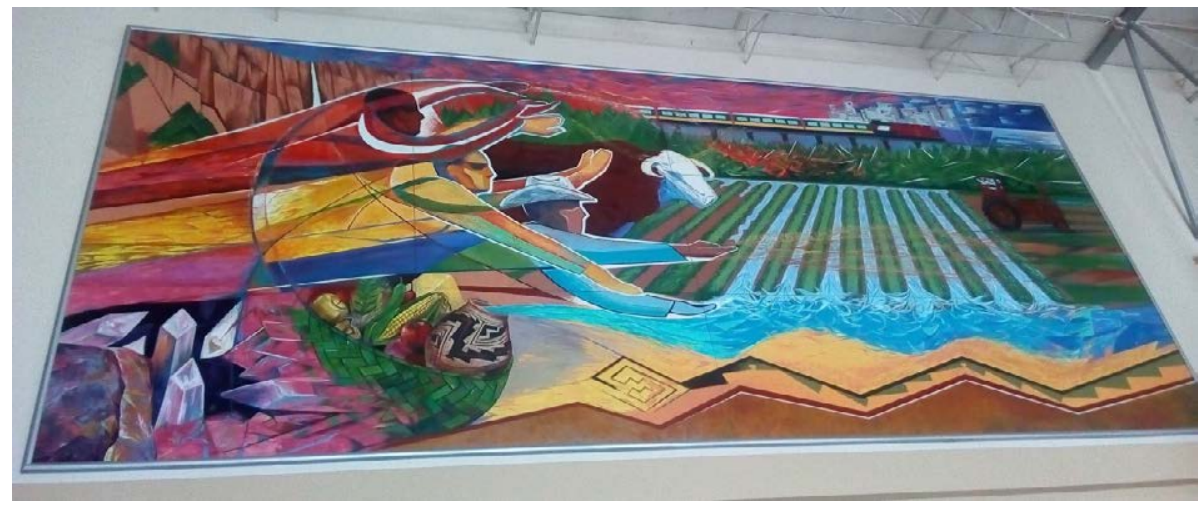

Fuente: (Liddiard, 2018). 
El que la etnia indígena propia de una comunidad se represente en su arte mural como iconicidad no es un asunto privativo de la ciudad de Chihuahua. En su artículo, Le Mur (2016) documenta como en Guadalajara, Jalisco, los jóvenes que practican el grafiti y demás artistas urbanos retratan en sus obras aspectos huicholes, o wixárikas, integrando la imagen e identidad de esa etnia en el espacio citadino de la urbe del occidente de México.

\subsection{Comparativa}

En la composición del mural de la imagen 2, se puede observar también otro aspecto de interés que genera incluso su propia categoría en este documento. Es el uso de la imagen del rarámuri como comparativa hacia otros grupos humanos chihuahuenses, en este caso el español y el mestizo, pero que puede incluir al menonita, grupo religioso y étnico de origen suizo asentado en el estado de Chihuahua desde 1922 (Sen Venero, 1999), e incluso a otras etnias representativas de la región.

En el mural presentado en la imagen 3, pintado por el artista urbano Troll en la intersección de las avenidas De las Industrias y Teófilo Borunda de la ciudad de Chihuahua, se encuentra una ejemplificación clara de esto. Con cuatro personajes masculinos atravesando en fila un cruce peatonal -en evidente homenaje a la portada del álbum de 1969 de The Beatles, Abbey Road-, el artista estereotipa los cuatro grupos humanos que para él cimentan al estado de Chihuahua: el rarámuri, el menonita, el apache y el mestizo caracterizado de vaquero; haciéndolo por medio de sus vestuarios típicos, elemento básico para la expresión interpretativa de personajes en el arte (Amador, 2008). De esta manera, y aludiendo un mensaje de integración comunitaria, este mural y algunos otros a lo largo de la ciudad hacen un comparativo visual humano, mostrando con rasgos obvios lo multirracial que es la población chihuahuense.

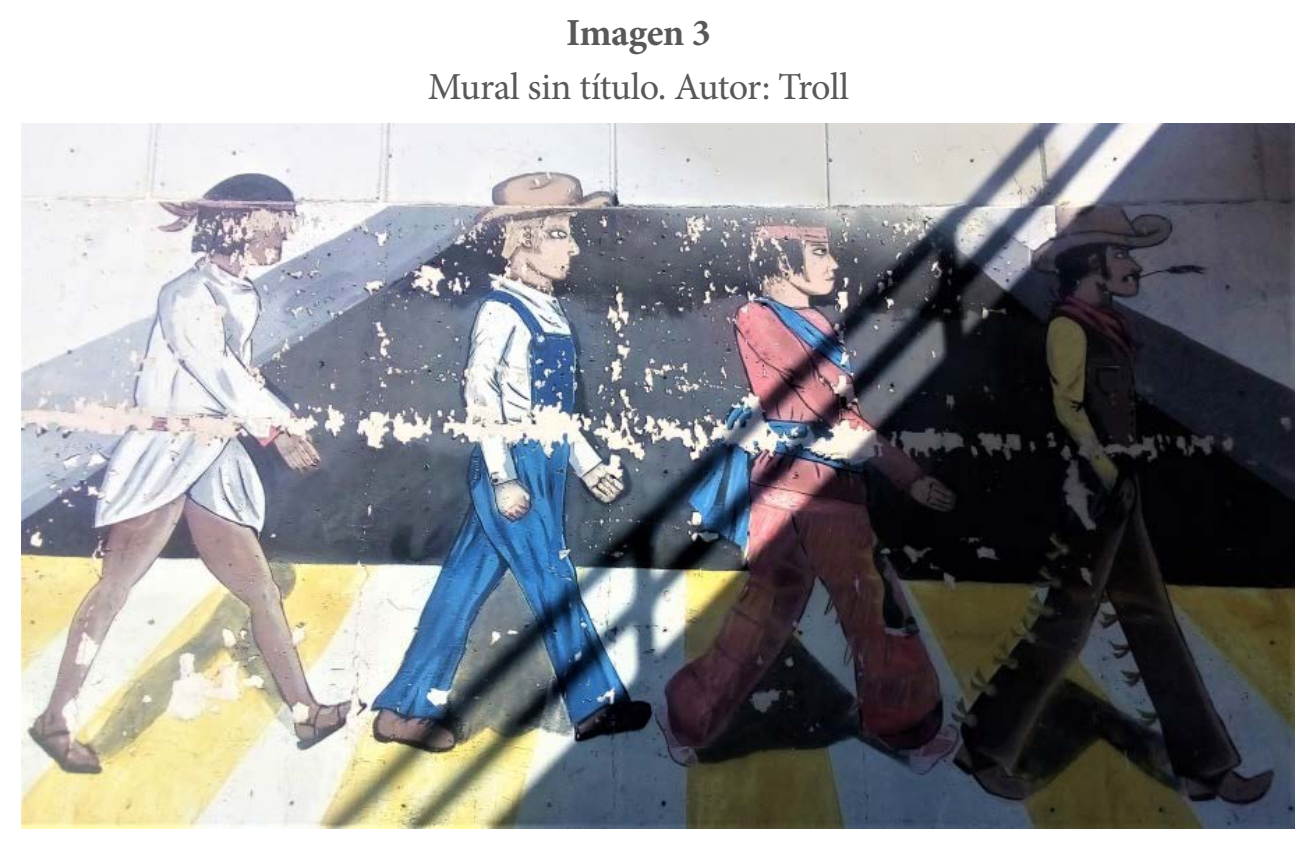

Fuente: (Liddiard, 2018). 


\subsection{Naturalista}

Otro tipo de representación común es la que muestra al rarámuri dentro de su entorno natural, precisamente en la Sierra Tarahumara, rodeado de la vegetación nativa, como lo son algunas variedades de coníferas, encinos, cedros y madroños, así como arbustos como mezquites y huizaches (Gotés et al., 2010), en un contexto sereno y reflexivo, y dentro de paletas cromáticas mayoritariamente verdes, azules o marrones. Incluso locaciones turísticas, como la Cascada de Basaseachi, son acompañamiento habitual de estas estéticas pinturas que en veces asemejan postales vacacionales.

Se aprecia que, desde el muralismo, la función en esta representación reside mayoritariamente en la reinterpretación de una conexión milenaria entre la comunidad rarámuri y el entorno natural chihuahuense, relacionando a la etnia con su cosmología. En el vestíbulo del edificio de la Dirección de la Benemérita y Centenaria Escuela Normal del Estado de Chihuahua Profesor Luis Urías Belderráin, o IBYCENECH, se encuentra el mural, Raíces, pintado por Manuel Castruita Heredia en 1996, el cual es un ejemplo de esta representación naturalista al presentar distintos y bellos escenarios de la Sierra Tarahumara, aunque sin quedarse en el preciosismo, realzando igualmente aspectos culturales y costumbres rarámuri, como el correr por extensos periodos, observado en la imagen 4.

\section{Imagen 4}

Mural, Raíces. Autor: Manuel Castruita Heredia

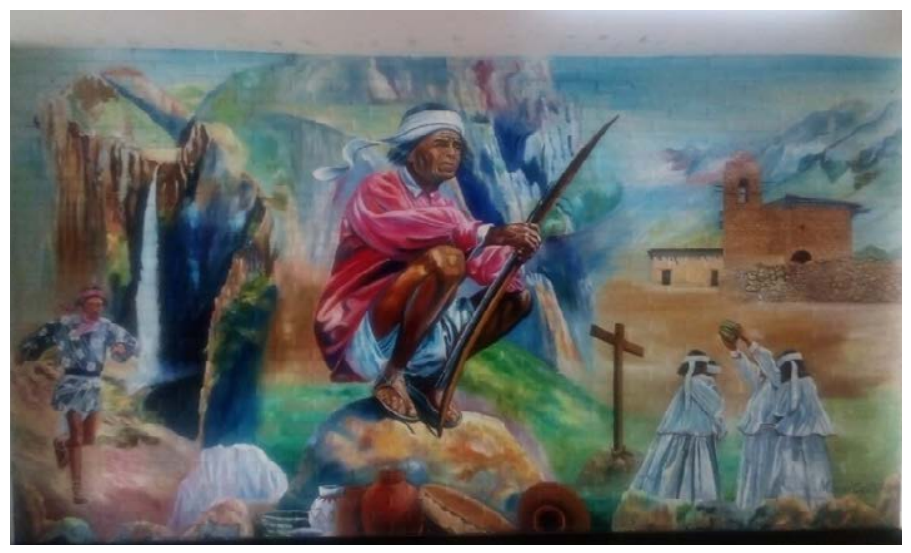

Fuente: (Liddiard, 2018).

\subsection{Citadina}

Si una de las representaciones de la comunidad rarámuri en el muralismo de la ciudad de Chihuahua se da en un entorno de naturaleza y paisajes serranos, es lógico pensar que su contraparte, la del tarahumara citadino, también tiene cabida en este medio de expresión, sobre todo en el contexto del arte urbano. Así, su vestimenta típica se mezcla con prendas modernas y occidentalizadas, y sus actividades características se transforman, como el jugar basquetbol en vez de correr, tal y como se apreciaba en el mural de la entrada del Centro Comunitario El Aliviane Gente Especial -pintura hoy ya desaparecidahecho por el Colectivo Los Mismos en 2012, y presentada en la imagen 5. 
Imagen 5

Detalle de mural sin título. Autor: Colectivo Los Otros

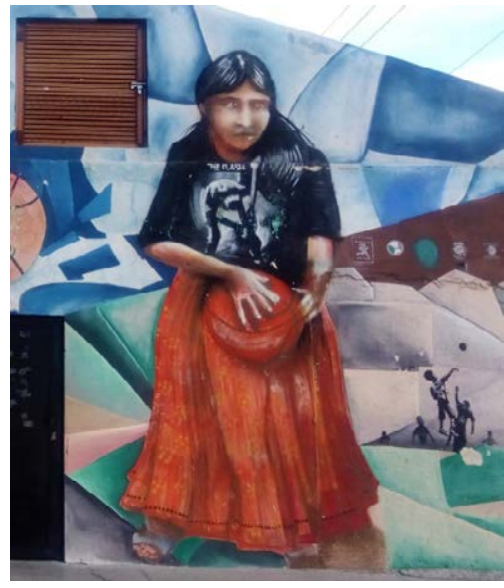

Fuente: (Liddiard, 2017).

Es la otra cara de la moneda, la del rarámuri interactuando con el chabochi de manera casual y cotidiana, sin los idealismos de lo histórico, ni plasmándolo como un ícono; sino real, humano, tal y como se le aprecia día a día en las calles de la ciudad. Advirtiéndolo con las funciones del lenguaje de Jakobson -en este caso visuales- se hablaría de una representación referencial (Vargas, 2015), directa a lo que el tarahumara es en la ciudad. Realista en contenido, y para el mural en la imagen 5, también en forma.

La representación citadina incluso puede verse como un replanteamiento del propio rarámuri y su identidad dentro de una sociedad ajena y dominante, ya que "la identidad de una comunidad se construye en la interacción de sus habitantes consigo mismos y con los demás.... La interacción con los otros asegura la construcción de la identidad más sólida al confrontar, converger y divergir" (Escudero et al., 2019, p. 177).

La ciudad ofrece a los rarámuri oportunidades de trabajo, educación y salud distintas a lo que pueden encontrar en su entorno serrano, pero igualmente les representa adquirir problemáticas inherentes a ella, que se suman a su condición de pobreza y marginalidad, propiciando ser empleados "en actividades étnicamente diferenciadas, minusvaloradas, mal remuneradas y sin beneficios sociales" (Morales, 2018, p. 70). El mismo autor añade que "la discriminación... hacia los rarámuri por parte de la sociedad chihuahuense es común; están sujetos a normatividades y legalidades urbanas que los sitúan en posiciones de desventaja; quienes residen en los asentamientos no son dueños de las viviendas" (p. 70), siendo potencialmente una temática pendiente a ser representada en el muralismo chihuahuense actual.

\subsection{Onírica}

En el anterior apartado se planteó un acercamiento por parte de lo citadino a la función referencial de Jakobson. Es posible entonces, desde la acotación de otra manifestación visual de la etnia rarámuri, dirigir la reflexión hacia la función poética; referente a lo onírico, incluso surrealista (Vargas, 2015) en algunas obras chihuahuenses de este tipo. 
$\mathrm{Al}$ ser plasmada la imagen del rarámuri como parte de una figuración más allá de lo natural, pierde en realismo pero gana en riqueza simbólica. Su interpretación, sacada de la fantasía del autor o autores, mezcla elementos distorsionando la racionalidad, y jugando con una ambigüedad propia de la poesía, en este caso visual. Los atributos estéticos y artísticos son los que resaltan por sobre los contextuales y de contenido, con elementos visuales como colores y formas, que transmiten emoción y sensibilidad (Castiñeiras, 2007; Vargas, 2015).

En una composición que avista la ficción matizada con antecedentes comunes y conocidos -aunque no siempre comprensibles para el espectador- se dan únicamente pistas de lo que el mensaje puede llegar a significar, ahora involucrando la imagen del rarámuri y generalmente su cosmovisión de la vida. Aunque como se puede advertir, al reinventar el artista códigos de información ya reconocidos, la ambigüedad puede ser tal que lleve a una mala interpretación del mensaje; pero en lo onírico esto es una situación común y previamente considerada.

Las características mencionadas se encuentran ejemplificadas en un par de obras, parte del conjunto mural creado por el Colectivo Tomate en el marco del Festival Internacional de la Ciudad de Chihuahua 2019, esto en el Centro Histórico de Chihuahua. Particularmente en el mural observado en la imagen 6, realizado por Mar de Lio, se expone una serie de elementos acompañantes al busto de una mujer rarámuri, como un pedazo de tierra coronado con una planta floral que nace de su mano, o un corazón humano flotante con hojas saliendo de sus conductos arteriales. Esto ofrece un indicio interpretativo hacia una figuración de la Madre Naturaleza, apersonada en la feminidad rarámuri y su conexión ancestral con lo natural.

Imagen 6

Mural sin título. Autora: Mar de Lio

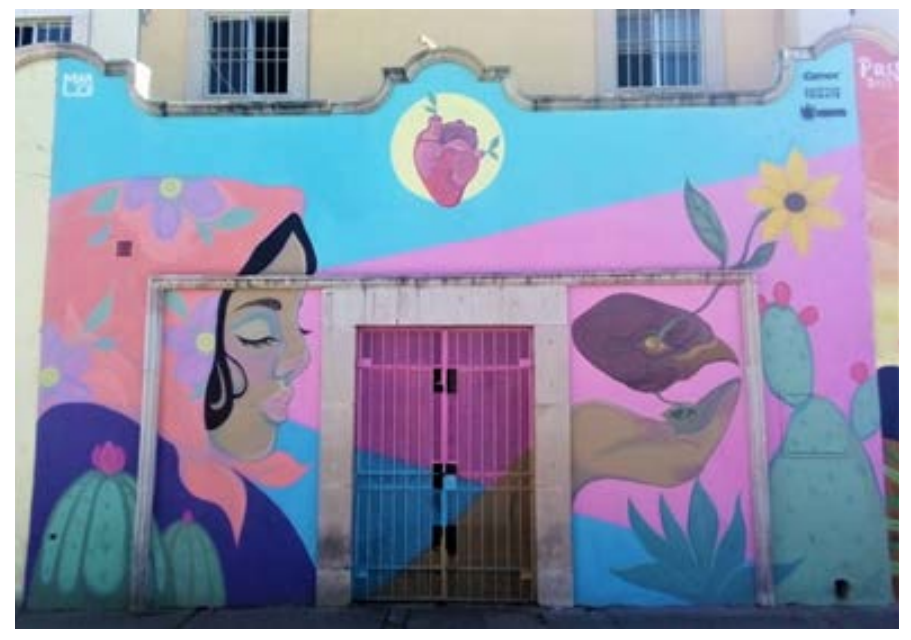

Fuente: (Liddiard, 2019).

Otro ejemplo de esta representación onírica puede encontrarse en el hermoso mural en homenaje a la poetisa rarámuri Dolores Batista, realizado por el Colectivo División Norte en 2020, también en el Centro Histórico. En este, el retrato de cuerpo completo de la protagonista se encuentra sentado en un 
trono mientras la gigantesca naturaleza a su alrededor le rinde pleitesía, una reinterpretación visual a su poema, Canción de las flores de México, anexo incluso en el mural, el cual presenta una paleta cromática psicodélica, propia de este colectivo y su gusto por lo surreal.

\subsection{Caricaturizada}

La última representación a resaltar de la etnia rarámuri es la caricaturización, o la plasmación de miembros de esta comunidad con trazos propios de la caricatura, o en su caso el anime japonés. Su uso está básicamente focalizado en los murales urbanos, esto por la frescura y el desenfado en el que se desenvuelven, pero a la vez conlleva una falta de seriedad que genera ocasionales críticas hacia sus creadores.

El mural titulado, Chihuahua por sus tradiciones, presentado por Diana Estrada en 2017 para el programa muralista de Gobierno del Estado de Chihuahua, Yo Amo Chihuahua, expuesto en la imagen 7, es un ejemplo de esto, al incorporársele el retrato de una joven tarahumara elaborado con esta particular forma de arte, que acentúa a su manera sus rasgos característicos dentro de un gesto de inocencia y alegría. El asociar trazos no tan formales con imágenes humanas, acerca el mensaje a un público más joven, más identificado a este estilo visual.

\section{Imagen 7}

Mural, Chihuahua por sus tradiciones. Autora: Diana Estrada

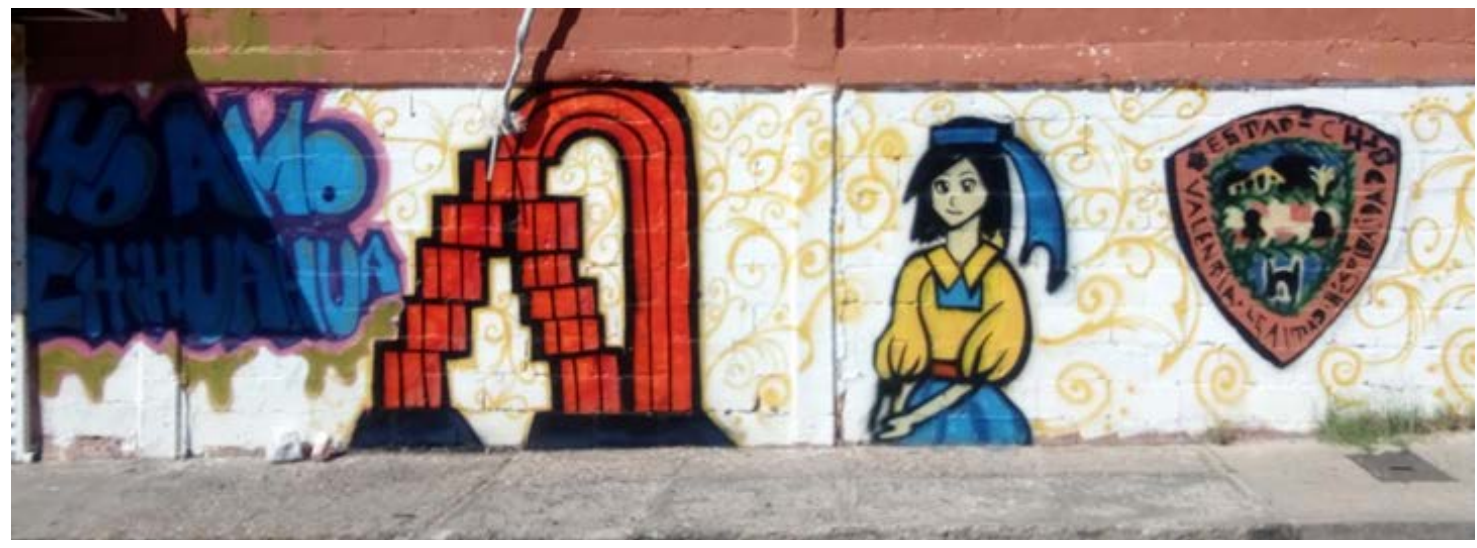

Fuente: (Liddiard, 2017).

Como se puede constatar en este mural de la imagen 7, el retrato de la joven está flanqueado por la escultura, Puerta de Chihuahua, del artista camarguense, Sebastián, y por el Escudo de Chihuahua; ambos elementos chihuahuenses reconocidos, uno capitalino y el otro estatal. Esto lleva a reflexionar que la pintura entra también en la categoría de icónica, concluyendo que las siete representaciones expuestas no se excluyen entre ellas. Al contrario, pueden ser complementarias, siempre y cuando estén en función del mensaje, como se mencionó anteriormente.

Otro ejemplo de esto es el mural, La diversidad y la unidad en las etnias, hecho por Carlos Martínez también para el programa Yo amo Chihuahua, donde igualmente con trazos caricaturizados se plasma 
a una mujer tarahumara y dos niños a los que toma de las manos, uno menonita y otro mestizo. Se entiende entonces que integra tanto la representación caricaturizada como la comparativa, desplegando amenamente el mensaje de unión entre los distintos grupos humanos chihuahuenses.

\section{Conclusión}

Los murales en la ciudad de Chihuahua cuentan entre sus múltiples elementos, imágenes de personajes de la comunidad rarámuri, todos representados de maneras variadas según las necesidades y estilo del artista en turno. La importancia de esta etnia al imaginario cultural visual chihuahuense salta a la vista en esta reducida muestra visual presentada, y toma fuerza al recordarse que el muralismo es solo un medio más donde puede encontrarse.

El análisis iconográfico desde el método seleccionado comienza desde la comprensión de los elementos visuales primarios, formas y colores, como componentes informativos en la composición de la obra plástica. Así mismo, el descifrar la simbología manejada es parte importante en el quehacer iconográfico. Pero son particularmente los elementos narrativos de la escena, la que haya sido seleccionada por el artista, los que brindaron las herramientas para la catalogación de las representaciones rarámuri. Los rasgos y actividades propias de los personajes, el vestuario y sus accesorios, el contexto del escenario alrededor, e incluso el lenguaje corporal manifestado, son también fuentes de información que dieron pauta para reconocer diferencias y similitudes entre obras.

A lo largo del análisis y la catalogación de las representaciones muralistas rarámuri se aprecia una relativa visión neutral y armoniosa, de relación interétnica entre el tarahumara y su contraparte chabochi. Se explica debido a que el mensaje que los mismos muralistas chihuahuenses han querido plasmar en sus obras es de armonía en el contexto social, más que de conciencia crítica a la temática rarámuri en particular, creando las pinturas optimistas que hoy decoran edificios y colonias de esta urbe, pero principalmente su Centro Histórico, punto de reunión turística.

Esto por supuesto no desaparece la problemática social con la que vive la comunidad rarámuri en la ciudad de Chihuahua, ni las condiciones de desigualdad en las que subsiste como grupo vulnerable reconocido. El que esta etnia se observe como un referente visual de lo chihuahuense, tanto fuera, pero primordialmente dentro del estado y su capital, no asegura que este reconocimiento salga de la pared, la pantalla o la hoja impresa. Todavía hoy los grupos indígenas son transgredidos en algunas de sus necesidades, acarreándoles esto problemas económicos y de violencia.

La reflexión va entonces a que esta visualización sobrepase los muros y afecte a las personas reales, fuera de los pinceles y las latas de pintura. En lo que toca al muralismo de la ciudad de Chihuahua, existen múltiples obras, sobre todo urbanas y en el marco de programas gubernamentales, que trabajan desde la crítica a varios problemas sociales, como la drogadicción, la violencia familiar, la criminalidad, entre otras. Las representaciones de lo rarámuri están ya en la pared, algunas con tintes de apropiación cultural. Queda esperar a que la consciencia hacia los problemas que afectan la comunidad que las inspiró entre también en la reflexión social y artística.

Para finalizar, se concluye que para lograr el acercamiento a una visualización de la cultura rarámuri, se requieren de todas las ópticas posibles, inclusive la muralista. Dar cuenta de una catalogación y un análisis interpretativo para estas siete distintas y acotadas representaciones, es sumarse al esfuerzo cons- 
tante de acceder a una aproximación más de la identidad de este pueblo indígena, aunque sea a través de los ojos de los artistas. Así mismo, ofrecer referencias hacia próximos trabajos iconográficos/sociales en otros puntos geográficos, en pos de ampliar y enriquecer la discusión sobre el tema.

\section{Referencias}

Amador, J. (2008). El significado de la obra de arte: Conceptos básicos para la interpretación de las artes visuales. Universidad Nacional Autónoma de México, Dirección General de Publicaciones y Fomento Editorial.

Bajas, M. P. (2006). La transfiguración de la imagen, el artista, su obra y el espectador. Magallanía, 34(2), 11-19. https://www.redalyc.org/pdf/506/50614616002.pdf

Castiñeiras, M. A. (2007). Introducción al método iconográfico (3ra edición). Editorial Ariel.

Collin, L. (2003). Mito e historia en el muralismo mexicano. Scripta Ethnologica, (25), 25-47. https:// www.redalyc.org/pdf/148/14802502.pdf

Comisión Estatal para los Pueblos Indígenas. (Julio de 2017). Programa Sectorial para los Pueblos Indígenas 2017-2021. Comisión Estatal para los Pueblos Indígenas. http://www.chihuahua.gob.mx/ atach2/programa_sectorial_2017-2021.pdf

Escudero, R. A., Trujillo, J. A., y Pérez, F. A. (2019). Identidad y cultura: Un viaje a las raíces rarámuri. Boletín Redipe, 8(6), 174-184. https://revista.redipe.org/index.php/1/article/view/770/707

Espinoza, A. (2004). Tierras bárbaras. Navegaciones sobre la identidad chihuahuense. Plaza y Valdés Editores.

Feria, M. F., y Lince, R. M. (2010). Arte y grupos de poder: El muralismo y la Ruptura. Estudios Políticos, 9(21), 83-100. http://www.redalyc.org/articulo.oa?id=426439542004

Fernández, C. A., y Sen Venero, M. I. (2013). Los murales del Palacio de Gobierno de Chihuahua. Talleres Gráficos del Estado de Chihuahua.

Garrido, E. (2009). La pintura mural mexicana, su filosofía e intención didáctica. Sophia, Colección de Filosofía de la Educación, (6), 53-72. https://www.redalyc.org/pdf/4418/441846107004.pdf

Gotés, L. E., Pintado, A. P., Olivos, N., Pacheco, A., Morales, M. V., y De la Parra, D. (2010). Los pueblos indígenas de Chihuahua. Atlas etnográfico. Instituto Nacional de Antropología e Historia, Gobierno del Estado de Chihuahua. https://mediateca.inah.gob.mx /islandora_74/islandora/object/libro\%3A444

Instituto Nacional de Estadística y Geografía. (2015). Panorama sociodemográfico de Chihuahua 2015. Encuesta Intercensal 2015. Instituto Nacional de Estadística y Geografía. http://internet.contenidos.inegi.org.mx/contenidos/Productos/prod_serv/contenidos/espanol/bvinegi/productos/nueva_estruc/inter_censal/panorama/702825082161.pdf

Íñiguez, L. (2001). Identidad: De lo personal a lo social. Un recorrido conceptual. En Eduardo Crespo (Ed.), La constitución social de la subjetividad (pp. 209-225). Catarata. https://www.researchgate. net/publication/275154262_IDENTIDAD_DE_LO_PERSONAL_A_LO_SOCIAL_UN_RECORRIDO_CONCEPTUAL

Korsbaek, L., y Sámano, M. Á. (2007). El indigenismo en México: Antecedentes y actualidad. Ra Ximhai, 3(1), 195-224. http://revistas.unam.mx/index.php/cronicas/article /viewFile/50263/45119

Le Mur, R. (2016). La imagen wixárika en el arte mural de Guadalajara. Nueva Época, (26), 123-144. http://www.scielo.org.mx/scielo.php?pid=S0188-252X2016000200123\&script=sci_arttext 
Morales, M. V. (2013). Las prácticas de intervención institucional en la creación y organización sociopolítica de los asentamientos rarámuris en la ciudad de Chihuahua. El caso de El Oasis. Relaciones. Estudios de Historia y Sociedad, (134), 19-55. http://www.revistarelaciones.com/index.php/relaciones/article/view/459

Morales, M. V. (2018). Etnicidad y nuevos espacios de participación política y ritual de las mujeres Rarámuri en los asentamientos de la ciudad de Chihuahua. Andamios. Revista de Investigación Social, 15(36), 67-91. http://www.scielo.org.mx /scielo.php?script=sci_abstract\&pid=S1870$00632018000100067 \& \operatorname{lng}=$ es\&nrm=iso

Panofsky, E. (1979). El significado de las artes visuales. Alianza Forma.

Ramírez, J. (2020). Vida y sueños de la Cañada del Río Perla (1998). La pintura mural como medio para la autodeterminación cultural de las comunidades. Discurso Visual, (45), 163-170. http://www. discursovisual.net/dvweb45/PDF/18_Vida_y_suenos_de_la_Canada_del_Rio_Perla_1998_La_ pintura_mural_como_medio_para_la_autodeterminacion_cultural_de_las_comunidades.pdf

Rascón, E. (2011). Muros de identidad. Pinceladas de nuestra historia. Instituto Chihuahuense de la Cultura. Sen Venero, M. I. (1999). Historia de Chihuahua. Centro Librero La Prensa.

Solorio, N., y Trujillo, J. A. (2019). Historia breve de cuatro asentamientos rarámuri de la ciudad de Chihuahua. Debates por la Historia, 8(1), 111-142. https:/vocero.uach.mx/index.php/debates-por-lahistoria/article/view/391/389

Vargas, E. (2015). Las funciones del lenguaje de Jakobson en la titulación deportiva: Estudio estilístico de La Nación y La Extra. Filosofía y Lingüística, 41(1), 143-156. https://revistas.ucr.ac.cr/index.php/ filyling/article/view/21194/21356 

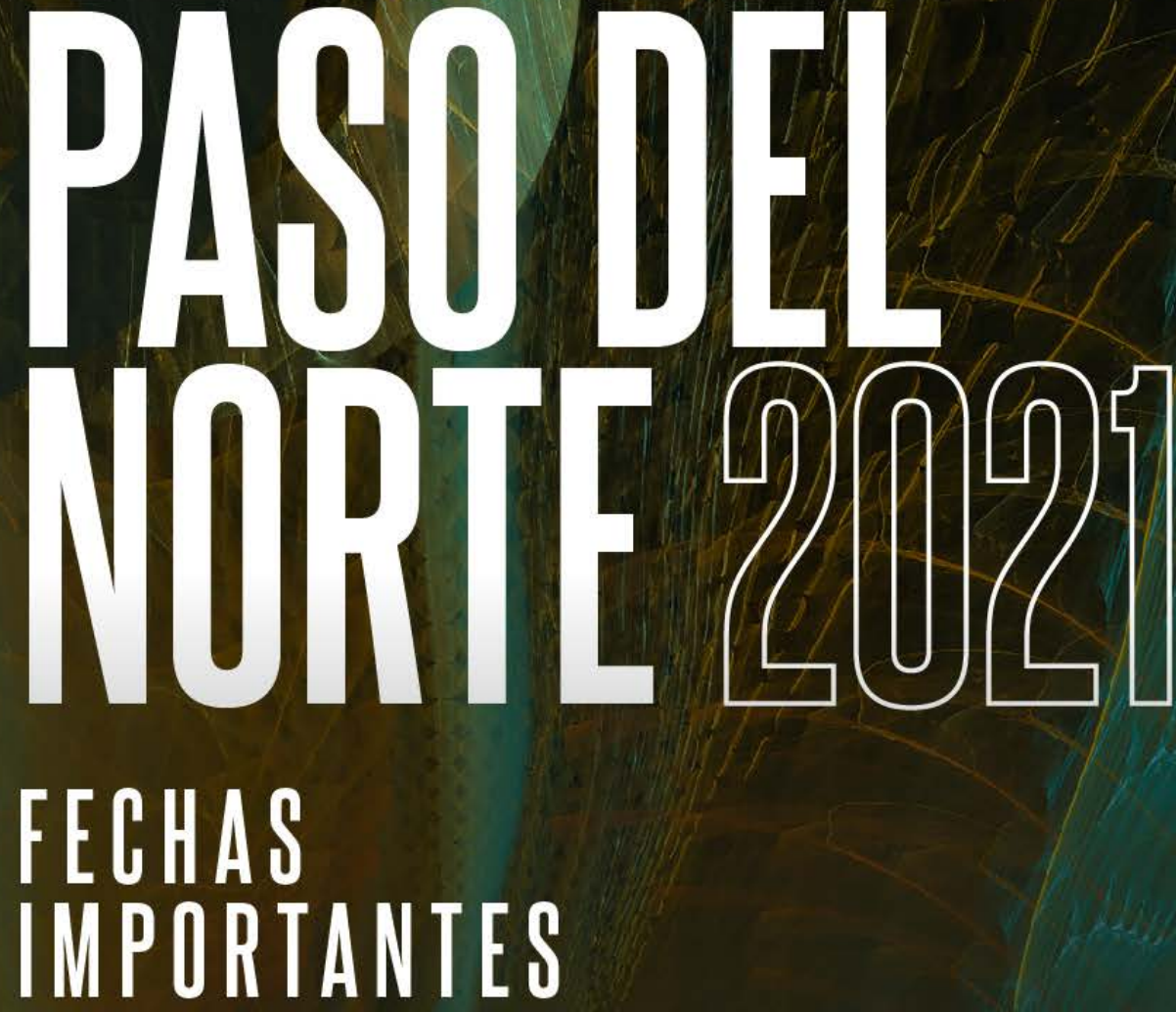

Recepción de trabajo

Del 15 de febrero al 7 de junio

Publicación de propuestas aceptadas 30 de julio

\begin{tabular}{ll}
\hline Fecha límite envío ponencias in extenso & $\mathbf{3 0}$ de septiembre \\
\hline Fecha límite de inscripción para ponentes & $\mathbf{8}$ de octubre \\
\hline Publicación del programa del Congreso & $\mathbf{2 2}$ de octubre \\
\hline Realización del Congreso & del $\mathbf{8}$ al $\mathbf{1 1}$ de noviembre \\
\hline Fecha límite para trámite de constancias & $\mathbf{3 0}$ de noviembre
\end{tabular}

Fecha límite para trámite de constancias

30 de noviembre

Registro de trabajos:

http://info.uacj.mx/congresocs2021 